We are glad that the danger from electrostatic induction is recognised. Danger exists from electrostatic induction for a distance of about 400 yards on each side of the $132 \mathrm{kv}$. lines. The maximum allowable pressure induced in a communication line has been fixed by the I. C. C. as 300 volts. Formulæ are given by the I. C. C. to enable the induced electromotive force to be computed. They are given in terms of Bessel's functions, but as these functions are written in the form $J(x, y)$ and are apparently functions of two variables, we fail to understand what they mean. It is stated with great emphasis that it has been definitely decided that, from the point of view of interference with communication circuits, the earthed neutral system is better than the insulated neutral system. There is nothing new in the statement that the resistivity of the matter forming the earth's surface is a predominant feature in determining the induced voltage. This was known many years ago. As a matter of fact the electrical resistivity of the surface ground varies from day to day.

The problems that will arise in connexion with this huge network of overhead wires have hitherto received little consideration. Its capacity to earth cannot be neglected, as it is very large. If it were insulated at every point, then if it sparked to earth the high pressure behind the spark would maintain a continuous arc the current in which might easily be hundreds of amperes. In the Bayernwerk network in south Germany (1250 miles of overhead wires) the capacity current in the arc has been computed to be between 500 and 600 amperes. It is stated, however, in A. E. G. Progress that the Petersen coils suppress the arcing flame at the faulty point almost instantaneously.

Standard substations of six types have been adopted. The minimum spacing between conductors of different phases is nine feet. All the transformers are designed for outdoor working. If their capacity exceeds $30,000 \mathrm{kva}$., then owing to the difficulties of transport they are made up of three single-phase units star connected. They are all provided with voltage- regulating equipment. Transport considerations made it necessary to use extremely strong tanks, as each transformer has to be capable of being transported completely immersed in oil by rail, road, and sea.

In the Scottish system the River Forth is crossed near Kincardine by a span 3050 feet in length. The suspension towers are each 338 feet high and the high-water clearance is 158 feet. The span is anchored at each end on 60-foot towers. Double chains of suspension insulator units are used. Each chain consists of 11 insulators. The total working stress is $20,000 \mathrm{lb}$.

An excellent map is given of the projected scheme of high-tension transmission lines for Great Britain. The Scotch scheme, which is nearest completion, shows that Carlisle, Edinburgh, and Glasgow will all be connected by a ring main. There are four large hydroelectric stations between Dundee and Inverness. The concentration of large stations on the Clyde is noticeable. Between Liverpool, Manchester, Leeds, and Sheffield there are many large power stations, and similarly round Birmingham and in London. Cambridge will be in direct connexion with Lincoln and London. Along the south coast of England the transmission lines will extend from Plymouth to Folkestone through Southampton. From Southampton they will extend to Bristol, Worcester, Cardiff, and South Wales. In North Wales there are several large hydroelectric generating stations, but these are not in connexion with the grid.

A few tables of the constructional costs for Scotland are given. For normal lines the costs of the lattice towers account for nearly half the total costs. The costs of the conductors are 30 per cent, and of the insulators 11 per cent of the total. The costs of the large high-tension transformers used average about 14 shillings per kilovolt ampere at 10,000 kva. size to about 5 shillings per kva. at $60,000 \mathrm{kva}$. size. The price of a small substation equipment averaged about $£ 20,000$. For larger substations the cost was about twice as much.

\title{
Structure of the Stars.
}

N Friday, Feb. 1, Prof. A. S. Eddington delivered the fifteenth Thomas Hawksley lecture before the Institution of Mechanical Engineers, on "Engineering Principles in the Machinery of the Stars." In introducing a general account of his well-known theory of the internal constitution of the stars, Prof. Eddington remarked that although modern physies is tending to show that engineering principles are not fundamental in the constitution of the universe, yet Nature does contrive to produce engineering work on the grand scale, much of which is exemplified in the structure of the stars. He then proceeded to amplify this statement by regarding a star as a power station, and considering the questions of its equipment and fuel supply.

The latter question is still in a very unsettled state, and although there are strong grounds for accepting provisionally the hypothesis that a star's heat is provided by the destruction of matter inside it, there are some observational results which are hard to reconcile with this. The lecture was framed in characteristic language, embodying Prof. Eddington's customary charm of expression. A typical example is the following statement of the somewhat recondite 'exclusion principle' of modern atomic physics :

"In general terms it means that every electron insists on being in some way a little bit different from its neighbours. So when pressure tries to insist on electron $A$ packing a little closer to electron $B, A$ replies 'No. We are already so nearly in the same position that people can only just manage to tell us apart.' But it is open to persuasion by an offer of some other distinction as a substitute for difference of position. If $A$ differs sufficiently from $B$ in energy or in momentum, that will do just as well. So at high temperatures when there is plenty of energy to go round, the electrons can distinguish themselves by seizing different quantities of it, and then they will not mind losing their distinction by position. Poor things! they are all turned out exactly to pattern by Nature's lathe, so they treasure these ways of insisting on their individuality - not to be just like one's neighbour. And so it comes about that at low temperatures the exclusion principle devotes its efforts to separating the electric charges in position and gives a large effective volume to the atom, whereas at stellar temperatures it is more concerned with distinguishing their momenta and energies, and is lax about keeping them apart in position."

Prof. Eddington referred to the possibility that a star might be regarded as being in "a rather remarkable state, namely, a crystalline gas." He does not think the gas inside a star is crystalline, but that it is not so far removed from that condition that we can leave the possibility out of all consideration. In any volume inside a star there are a few big positive charges (atomic nuclei) and a relatively much larger number of small negative charges (electrons). The former tend to take up a configuration of minimum energy, which is that of a crystal lattice, while the

No. 3093, VoL. 123] 
latter spread fairly uniformly over the volume. The energy of agitation tends to stir the material and 'melt' the crystal, but the crystalline state is a fair approximation to the actual condition. The gaseous character of the material would be manifested chiefly in its mechanical properties of expansion and compressibility, while the crystalline structure would appear chiefly in the optical properties.

A discussion of Cepheid variables regarded as pulsating stars occupied a considerable portion of the lecture. Although the difficulties of the conception have not been completely overcome, Prof. Eddington regards them as by no means serious. The problems set by such stars have led him to the view that the influence of temperature and density on the rate of liberation of sub-atomic energy must be an indirect one. "The energy is released from certain active substances formed inside the star ; the rate of formation of these substances increases with temperature and density, but they break up and liberate the energy at a rate unaffected by temperature and density."

\section{Museums and Education.}

YIR HENRY A. MIERS accomplished a great work for the museums of Great Britain when he wrote his report for the Carnegie Trustees, but that report was designed more particularly for museum committees and museum curators, and its appeal was for the specialist rather than the public. Now Sir Henry adds a second to his former accomplishment, for he has gone out into the wilderness to preach the gospel of museums to the people. This is as it should be, for it is to the apathy of the public and the dislike of intellectual effort, observable even where first-rate museums offer no excuse for it, that much of the inefficiency of museums can be traced.

On Jan. 23, Sir Henry Miers delivered an address on "Museums and Education" to the Royal Society of Arts, when the Right Hon. The Earl of Crawford and Balcarres, himself known for his wide interests in museums, was in the chair. Readers familiar with the strictures of the report will be prepared to learn that his address was not a gospel out and out, but underlying the very just criticisms which he made of certain types of museums, of curators, and of the public, lay a deep current of optimism in the educational possibilities of museums, and in a rejuvenated future in which they would take their due place in the development of the nation's outlook and thought. His address fell into two broad sections : in the first, he displayed the weaknesses and inefficiencies of many museums as they now exist, and showed how these had a direct and unfavourable repercussion upon the people's museum outlook. In the second, he pointed the way in which steady improvement might be made, by a reorganisation of museums towards special ends.

Sir Henry Miers' general criticisms of local museums as they are are familiar to readers of Nature. He summed them up in the course of his lecture: "There are many signs of improvement in the general situation, but, when all is said, it must be confessed that the large majority suffer from overexhibition, lack of policy, and the fatal habit of accepting miscellaneous gifts, so that of the service which they might render throughout the country a very small part is actually fulfilled by them."

Perhaps it is more profitable to dwell on Sir Henry's constructive suggestions. $\mathrm{He}$ founded his proposals on the proper assumption that museums are designed for the use of four distinct categories of visitors : the ordinary, more or less casual, visitor; the local student, whether he be of ripe years or an elementary scholar; the definite and purposeful collector and inquirer; and the scientific research worker. Not every museum can cater for each of these groups, but the principle of appeal for any group ought to be similar wherever it has a place. Thus it is most fitting that for the ordinary visitor the nature and resources of the town or district should be displayed, the labelling should be thorough yet simplein word, and easy transitionsshould lead from one collection to another of different kind.

For school children and older scholars, summary collections or introductory series are desirable, and Sir Henry said a true word when he stated that the writing of lucid, accurate, and short labels is a very difficult task, requiring much eare and thought, and, we would add, experience. For the collector, the introductory series must be supplemented by systematic collections, and for the research worker, to these must be added great stores of classified and authenticated material.

A strong appeal was made for the strengthening of the Museums Association, as a correlating body, for the extension of interaction and inter-lending between the national and local museums, and for the creation of a type of museum new to Great Britain, the "folk museum,' which would depict in complete units the life of English (why not British ?) people through the ages.

\section{Culture Sequence in the Swiss Lake Dwallings.}

WING to lack of supervision and organisation in the earlier explorations of the Swiss lake dwellings, chronological data relating to the finds are scant. As, however, investigations were for the most part of a superficial character, many sites were left undisturbed except for the topmost layer. Some of these have now been explored by M. Vouga under the auspices of the Neuchâtel Committee for Archæological Research. A summary of the results is given in Antiquity for December.

The civilisation of the Swiss lake dwellings up to and including the Copper Age is represented by two phases. The older appears in a single stratum, while the second consists of two or three superimposed. These are distinguished as lower, middle, and upper Neolithic and Eneolithic ages. They are separated each from each by a barren layer of a certain thickness. It is to be noted that in the deposit of the first occupation, which always rests on the lacustrine bed, the objects found are for the most part of a much more advanced technique than those found in the upper layers. This is particularly true of the pottery, which reaches a high grade of excellence. Here, too, the flint is dark brown, semi-transparent at the edges, and not the opaque white, dusky, or black local product. The spindle-whorl seems unknown.

The middle Neolithic has been called the bel âge de la pierre, but that appellation must now be abandoned in view of the finds in the hitherto neglected lower Neolithic. It is, however, still the most important settlement, its deposit sometimes being a metre thick. The remains of the habitations have generally been destroyed by fire. Its flint work is richer and more varied than in the early stratum, the 'type-fossil' being the arrow-head. The pottery has degenerated, and gives the impression of an art in its infancy.

The upper Neolithic is a normal evolution of the middle, of which it represents merely an advanced 